\title{
Relação do Ciclo de Vida Organizacional com o Planejamento: um Estudo com Empresas Prestadoras de Serviços Contábeis do Estado de Santa Catarina
}

\section{Resumo}

O estudo objetiva identificar a relação dos diferentes estágios do ciclo de vida organizacional com o processo de planejamento das empresas prestadoras de serviços contábeis do Estado de Santa Catarina. Pesquisa descritiva com abordagem quantitativa foi realizada por meio de pesquisa de levantamento em uma amostra por acessibilidade em 116 empresas. Para tanto, utilizou-se do modelo de Miller e Friesen (1984) para identificar os estágios de ciclo de vida e do instrumento de Frezatti, Relvas, Nascimento, Junqueira e Souza (2010) para mensurar o nível de utilização dos artefatos do planejamento. O planejamento foi analisado em suas três modalidades: Planejamento Estratégico, Orçamento e Controle Orçamentário. Para a análise dos dados, utilizou-se da análise discriminante e de correlações. Os resultados do estudo mostraram que as empresas prestadoras de serviços contábeis estão classificadas em distintos estágios de ciclo de vida organizacional, com predominância no nascimento e no rejuvenescimento. Apenas a metade das empresas analisadas utiliza-se do orçamento, mesmo sendo dirigidas por pessoas da área e que conhecem da importância deste instrumento. Observou-se ainda que existe uma correlação negativa entre os estágios de nascimento e declínio e a utilização dos artefatos de planejamento e uma correlação positiva entre os estágios de crescimento, maturidade e rejuvenescimento, convergindo com os resultados de Miller e Friesen (1984).

Palavras-chave: Ciclo de Vida Organizacional. Controle Orçamentário. Prestadoras de Serviços Contábeis. Orçamento. Planejamento Estratégico.

\author{
Dinorá Baldo de Faveri \\ Doutoranda em Economia pela Universidade \\ Federal de Santa Catarina (UFSC) e \\ Professora da Universidade do Estado de \\ Santa Catarina (UDESC). Contato: Rua \\ Dr. Getúlio Vargas, 2822, Bela Vista. CEP.: \\ 89140-000. Ibirama-SC. \\ E-mail:dinora.faveri@udesc.br \\ Paulo Roberto da Cunha \\ Doutor em Ciências Contábeis e \\ Administração pela Universidade Regional \\ de Blumenau (FURB) e Professor da \\ Universidade Regional de Blumenau \\ (PPGCC/FURB) e da Universidade do Estado \\ de Santa Catarina - UDESC. Contato: Rua \\ Antônio da Veiga, 140, Victor Konder. CEP.: \\ 89012-900. Blumenau-SC. \\ E-mail: pauloccsa@furb.br \\ Vanderlei dos Santos \\ Mestre em Ciências Contábeis pela \\ Universidade Regional de Blumenau (FURB) \\ e Professor da Universidade so Estado \\ de Santa Catarina (UDESC). Contato: Rua \\ Dr. Getúlio Vargas, 2822, Bela Vista. CEP.: \\ 89140-000. Ibirama-SC. \\ E-mail: vanderlei.santos@udesc.br \\ Deivison Anselmo Leandro \\ Bacharel em Administração pela \\ Universidade Federal de Santa Catarina \\ (UFSC) e Administrador na empresa \\ Servitech Serviços Técnicos Representações \\ Ltda. Contato: Rua Dr. Getúlio Vargas, 2822, \\ Bela Vista. CEP.: 89140-000. Ibirama-SC. \\ E-mail: deivisonanselmo@gmail.com
}




\section{Introdução}

O aumento dos processos de produção e a acentuada concorrência mercadológica nos últimos anos têm exigido das organizações esforços em planejamento, controle e tomada de decisão. As organizações se viram obrigadas a modificarem as técnicas até então utilizadas, derivadas de outras áreas, com a intenção de explicar a complexidade do fenômeno organizacional e, por consequência, facilitar o entendimento de gestores (Ramos, 1981).

Entre os conceitos que visam a explicar a complexidade do fenômeno organizacional e que se alteraram em função de mudanças na realidade das organizações, tem-se o conceito de ciclo de vida que foi desenvolvido em um primeiro momento no campo das Ciências Biofisiológicas e, ao longo do tempo, tem sido aplicado em outras áreas, principalmente nas Ciências Sociais, por sua adaptação às questões referentes ao desenvolvimento, sejam de civilizações, culturas, línguas, entre outras (Freitas, Costa, \& Barroso, 2002).

Diante das mudanças e das adaptações necessárias à sobrevivência das organizações, se faz necessária a busca por novas estratégicas, estruturas e alterações nos estilos de tomada de decisões. As teorias do ciclo de vida organizacional são usadas para justificar mudanças estruturais e de comportamento. Assim, fazem uso da analogia entre o desenvolvimento das organizações com o ciclo biológico dos seres vivos, em que estes nascem, se desenvolvem e podem chegar ao fim, com o desaparecimento, ou seja, seu declínio (Adizes, 1996).

As etapas de desenvolvimento do ciclo de vida estão embasadas em estágios com características que são definidas ao longo da vida da organização. De acordo com estudos na área, a postura dos gestores e as práticas de gestão adotadas por eles podem influenciar as possibilidades de sucesso. Ao considerar o fato de que as práticas de gestão podem mudar os estágios de ciclo de vida, faz-se necessário conhecer essas práticas em cada estágio de desenvolvimento para aperfeiçoar a maneira como a organização é gerenciada, de modo a buscar seu crescimento e futura consolidação no mercado.

Apesar da existência de alguns modelos de ciclo de vida organizacional utilizados para estudar a evolução do seu crescimento, o modelo de Miller e Friesen (1984) tem se destacado na literatura, em que consideram cinco estágios para o ciclo de vida das organizações: nascimento, crescimento, maturidade, renascimento e declínio. Os autores realizaram testes empíricos e sua principal contribuição foi mostrar que não existe apenas uma sequência de desenvolvimento, o que permite a empresa regredir nos níveis de ciclo de vida.

A identificação de fases das organizações, via características ou padrões de comportamentos específicos relacionados com os estágios de seus desenvolvimentos, tem sido explorada por alguns estudiosos que procuram reconhecer padrões específicos, como complexidade, formalização, estrutura organizacional, tomada de decisão e critérios de eficácia em determinados momentos, que caracterizaram os vários estágios do ciclo de vida (Greiner, 1972, Kimberly, 1987, Machado da Silva, Vieira, \& Dellagnelo, 1992).

Os estudos de Kauffmann (1990) apontam que o desenvolvimento das organizações está relacionado ao perfil predominante no processo gerencial, incluindo a estrutura organizacional, o estilo de liderança, $o$ nível de burocracia e o modelo de delegação e autoridade. Além disso, conseguem identificar os mesmos estágios em diferentes organizações, mas todos sofrem alterações no tempo de duração do ciclo, bem como na maneira como aconteceu.

Pesquisas internacionais e nacionais têm sido desenvolvidas relacionando a teoria do ciclo de vida organizacional com a Contabilidade Gerencial. Frezatti, Relvas, Nascimento, Junqueira e Souza (2010) analisaram o perfil das empresas brasileiras no que se refere à estruturação do processo de planejamento, associado aos estágios do ciclo de vida organizacional. Para tanto, realizaram uma pesquisa de levantamento em 111 organizações de distintos setores. Os resultados do estudo mostraram que o Planejamento Estratégico foi evidenciado apenas no estágio da maturidade. Observaram também que não existe relação entre o controle orçamentário e os estágios de ciclo de vida.

Em uma pesquisa similar, Klann, Klann, Postai e Ribeiro (2012) analisaram o relacionamento entre os estágios do ciclo de vida organizacional e o processo de planejamento das empresas. A pesquisa foi realizada com 30 empresas do setor metalúrgico do Município de Brusque-SC. Os resultados da pesquisa 
mostraram que a maior parte das empresas pesquisadas situa-se nos extremos dos estágios de ciclo de vida organizacional, nas fases de nascimento e declínio. Concluíram que existe relação entre os estágios do ciclo de vida e o nível de planejamento utilizado pelas empresas, porém, os artefatos de planejamento são utilizados de maneira diferente, dependendo do estágio de desenvolvimento da empresa.

Entretanto, ainda não se localizou nenhuma pesquisa sobre ciclo de vida organizacional e a Contabilidade Gerencial contemplando apenas empresas prestadoras de serviços, mais especificamente, empresas prestadoras de serviços contábeis. Desta forma, emerge a seguinte questão de pesquisa: Qual a relação dos estágios do ciclo de vida organizacional pautado no modelo de Miller e Friesen (1984) com o processo de planejamento das empresas de contabilidade do Estado de Santa Catarina? Neste estudo, o processo de planejamento é analisado em suas três etapas: Planejamento Estratégico, Orçamento e Controle Orçamentário, conforme preconizado por Frezatti et al. (2010).

Estudos com as prestadoras de serviços contábeis já foram realizados na área da Contabilidade Gerencial, mais especificamente na utilização dos instrumentos gerenciais. Teixeira, Voese e Teixeira (2014) avaliaram o nível de utilização dos artefatos gerenciais pelas empresas de serviços contábeis, em resposta à sua gestão de competências. Mattos (2008) procurou identificar em qual estágio de evolução se encontram as práticas de Contabilidade Gerencial adotadas pelas empresas prestadoras de serviços contábeis de Curitiba e região metropolitana. Entretanto, essas pesquisas não contemplaram a análise do ciclo de vida organizacional dessas empresas. Assim, o objetivo geral desta pesquisa é identificar a relação dos diferentes estágios do ciclo de vida organizacional com o processo de planejamento das empresas prestadoras de serviços contábeis do Estado de Santa Catarina. Para tanto, estabeleceram-se três objetivos específicos: a) identificar os estágios do ciclo de vida organizacional pautados no modelo de Miller e Friesen (1984) das empresas prestadoras de serviços contábeis do estado de Santa Catarina; b) verificar o nível de utilização do processo de planejamento (Planejamento Estratégico, Orçamento e Controle Orçamentário) das empresas prestadoras de serviços contábeis do Estado de Santa Catarina; e c) relacionar os estágios do ciclo de vida organizacional pautados no modelo de Miller e Friesen (1984) com o processo de planejamento das empresas prestadoras de serviços contábeis.

Há ao menos duas razões pela escolha das empresas prestadoras de serviços contábeis. A primeira razão deve-se ao fato que a contabilidade se constitui de um importante instrumento que propicia informações úteis para a tomada de decisões por parte da gerência das organizações. Um segundo aspecto está relacionado ao profissionalismo do contador. Devido ao crescimento do setor de prestação de serviços contábeis, aumenta também a responsabilidade e a competência do gestor em garantir qualidade nos serviços como forma de se manter competitivo no mercado. Para manter-se no mercado também precisa traçar estratégias garantindo o crescimento de sua própria empresa.

Assim, como qualquer empresa que precisa ser gerenciada, as empresas que prestam serviços contábeis não são diferentes e carecem de planejamento, estratégias e competência dos gestores em ofertar serviços de qualidade e conseguir ao mesmo tempo se manter no mercado e competir com seus concorrentes. Nesse sentido, considera-se pertinente conhecer como acontece o ciclo de vida organizacional das empresas prestadoras de serviços contábeis, para identificar os padrões de comportamentos relacionados com os respectivos estágios. O presente estudo pode ser justificado ainda pela escassez de pesquisas nessa área e devido à importância das empresas prestadoras de serviços contábeis para a economia e a sociedade.

Com o tema proposto, pretende-se contribuir para a ampliação e aprofundamento do conhecimento científico sobre ciclo de vida organizacional e a contabilidade gerencial, especificamente nas empresas prestadoras de serviços contábeis. Pode ampliar também a compreensão sobre as práticas de planejamento adotadas, contribuindo para o sucesso e o crescimento destas empresas (Klann et al., 2012). Correia, Gomes, Bruni e Albuquerque (2011, p. 2) mencionam que: 
a identificação e a classificação do estágio do ciclo de vida organizacional contribuem com os gestores no posicionamento da empresa, no processo decisório, no desenvolvimento da organização e por consequência, na configuração do Sistema de Contabilidade Gerencial (SCG) mais adequado às necessidades da empresa.

O artigo está organizado, a partir desta seção introdutória, com mais cinco seções. A segunda e a terceira seção apresentam a revisão de literatura acerca do ciclo de vida organizacional e Controle Gerencial e Planejamento respectivamente. Adiante, tem-se a seção que apresenta as escolhas metodológicas, seguida da seção de análise e interpretação dos resultados encontrados. Por fim, têm-se as conclusões e sugestão para pesquisa futura.

\section{Ciclo de Vida Organizacional}

Conforme Catelli (2001), as organizações podem ser caracterizadas como sistemas abertos que estão em constante movimento e sofrem influências tanto do ambiente externo quanto interno. A adaptação dos conceitos das Ciências Biológicas à Administração fez com que fossem postulados muitos modelos de análise e avaliação do ciclo de vida organizacional no qual tem início no nascimento, ou na criação da empresa, e seu fim na morte ou dissolução dela. Esta adaptação por pesquisadores organizacionais remonta várias décadas (Greiner, 1972, Quinn \& Cameron, 1983).

Na visão de Marques (1994, p. 20), “a vida das organizações apresenta um razoável grau de semelhança com o ciclo de vida dos organismos vivos: nascem, têm infância e adolescência, atingem a maioridade, envelhecem e morrem." É por essa razão que muitos autores fazem uso da metáfora do organismo vivo para conceder nomes aos estágios do ciclo de vida. Devido às variações apresentadas nos estágios de ciclo de vida é que os pesquisadores buscam entender e avaliar a fase na qual a organização se situa para que dessa forma possam tomar medidas de precauções, se for necessário.

Assim como um ser humano possui necessidades, que se alteram em virtude de seu nível de desenvolvimento, as organizações também passam por determinadas etapas em cada estágio de desenvolvimento do seu ciclo de vida. À medida que as necessidades são supridas, a tendência é de que apareçam outras que, por sua vez, devem ser superadas para garantir o desenvolvimento de cada etapa.

No entanto, existe uma diferença marcante entre o ciclo de vida organizacional e um organismo vivo. De acordo com Marques (1994), enquanto o ser humano caracteriza suas fases de vida através do tempo, as organizações não seguem o mesmo padrão. Não que a analogia não possa ser feita, mas é preciso dedicar atenção às diferenças existentes para não cometer erros de interpretação.

Adizes (1996) comenta que tamanho e tempo não são causas de crescimento e envelhecimento; "empresas grandes, com longa tradição não são necessariamente velhas e empresas pequenas sem nenhuma tradição não são necessariamente jovens”. Adizes (1996) reforça que, a palavra “jovem” significa que a empresa tem capacidade de mudar com relativa facilidade, apesar de seu baixo nível de controle. Por outro lado, uma empresa "velha" consegue ser controlável, porém inflexível, com baixa propensão a mudar de comportamento. Assim, quando uma empresa é flexível e controlável ao mesmo tempo, ela não é nem jovem e nem velha. Nesse nível, adquire vantagens tanto de juventude quanto de maturidade, o qual se denomina de plenitude (Adizes, 1996). Os gestores conseguem identificar a situação e classificar as empresas de acordo com seu ciclo de vida. Saber identificar qual o estágio de desenvolvimento que uma organização se encontra pode auxiliar os gestores a entender as relações entre o ciclo de vida e estratégia competitiva. A literatura apresenta vários autores que têm abordado de diferentes maneiras o ciclo de vida organizacional e, por esse motivo, têm-se modelos de ciclo de vida diferenciados. O Quadro 1 sintetiza cinco desses modelos apresentados na literatura. 


\begin{tabular}{|c|l|l|}
\hline Autores/Modelos & \multicolumn{1}{|c|}{ Fases } & \multicolumn{1}{c|}{ Síntese do modelo } \\
\hline $\begin{array}{c}\text { Quinn e Cameron } \\
\text { (1983) }\end{array}$ & $\begin{array}{l}\text { - Estágio Empreendedor } \\
\text { - Estágio de Coletividade } \\
\text { - Estágio de Formalização e Controle } \\
\text { - Estágio de Formação de Estrutura }\end{array}$ & $\begin{array}{l}\text { Elaboraram um modelo síntese a partir da revisão } \\
\text { de outros nove modelos existentes. Buscaram } \\
\text { associar critérios de eficácia organizacional com as } \\
\text { fases do ciclo de vida. }\end{array}$ \\
\hline $\begin{array}{c}\text { Miller e Friesen } \\
(1984)\end{array}$ & $\begin{array}{l}\text { - Nascimento } \\
\text { - Crescimento } \\
\text { - Maturidade } \\
\text { - Renascimento } \\
\text { - Declínio }\end{array}$ & $\begin{array}{l}\text { Realizaram testes empíricos. Principal contribuição } \\
\text { foi determinar que não existe uma sequência } \\
\text { determinada de desenvolvimento e que é possível } \\
\text { retroceder nos estágios do ciclo de vida. }\end{array}$ \\
\hline $\begin{array}{c}\text { Baker e Cullen } \\
\text { (1993) }\end{array}$ & $\begin{array}{l}\text { Foco nos extremos, empresas jovens e pequenas } \\
\text { e empresas grandes e velhas. Investigaram o nível } \\
\text { de reorganização administrativa em empresas em } \\
\text { diferentes estágios do ciclo de vida. }\end{array}$ \\
\hline $\begin{array}{c}\text { Moores e Yuen } \\
\text { (2001) }\end{array}$ & $\begin{array}{l}\text { Desenvolveram um estudo baseado no modelo } \\
\text { de ciclo de vida de Miller e Friesen (1984), a fim } \\
\text { de verificar o nível de formalização do Sistema de } \\
\text { Contabilidade Gerencial, nas diferentes etapas do } \\
\text { ciclo de vida organizacional. }\end{array}$ \\
\hline $\begin{array}{c}\text { Lester, Parnell e } \\
\text { Carraher (2003) }\end{array}$ & $\begin{array}{l}\text { O modelo desenvolvido baseou-se no de Miller e } \\
\text { - Subrevivência } \\
\text { - Rejuvenescimento } \\
\text { - Declínio }\end{array}$ & $\begin{array}{l}\text { Friesen (1984) e foi elaborado para que pudesse ser } \\
\text { usado em qualquer tipo de organização. Buscaram } \\
\text { relacionar o ciclo de vida organizacional com } \\
\text { estratégia competitiva e desempenho. }\end{array}$ \\
\hline
\end{tabular}

Quadro 1. Modelos de ciclo de vida organizacional

Fonte: Marques (2011)

Neste estudo, optou-se pelo modelo de Miller e Friesen (1984). Ele foi escolhido por se tratar de um modelo amplamente conceitual, resultado de testes empíricos, e também contribuiu para determinar que não existe uma sequência de desenvolvimento e que é possível as organizações retrocederem nos estágios do ciclo de vida.

Miller e Friesen (1984) elaboraram uma categoria que pudesse ser útil para prever diferenças entre características ambientais e organizacionais (como diferenças na estratégia, na estrutura ou no estilo de tomada de decisão), em diferentes estágios do ciclo de vida organizacional. A principal motivação tem relação com o fato de os estudos existentes não possuírem uma base empírica sólida, pois foram realizados de forma cross-sectional, e assim identificavam características estáticas de diferentes organizações em diferentes estágios do ciclo de vida.

Beuren e Pereira (2013) analisaram 15 artigos que relacionam ciclo de vida organizacional e controles de gestão publicados em periódicos nacionais e internacionais. Os autores observaram que modelo para identificação do ciclo de vida mais recorrente nas pesquisas internacionais analisadas é o proposto por Miller e Friesen (1984). Além disso, os autores sinalizam que a abordagem do tema não é contínua, mas que ainda há espaço para publicações nos periódicos. Observaram também dispersão na autoria dos artigos sobre o tema e suas respectivas afiliações institucionais, tanto em âmbito nacional como internacional.

Após a realização de uma revisão bibliográfica, Miller e Friesen (1984) elaboraram um modelo de ciclo de vida organizacional composto por cinco estágios: nascimento, crescimento, maturidade, rejuvenescimento e declínio.

$\mathrm{Na}$ fase inicial, chamada de nascimento, é onde a empresa tenta se tornar viável. As principais características são: empresas jovens, dominadas por seus proprietários e com uma estrutura simples e informal. Scott (1971) chama essa fase de Estágio 1; Greiner (1972) a chama de Fase Criativa; Lippitt e Schmidt (1967) de Fase do Nascimento; e Quinn e Cameron (1983), de Fase Empreendedora (Miller \& Friesen, 1984). 
$\mathrm{Na}$ segunda fase, denominada Crescimento, tem-se a expectativa de que a empresa tenha estabelecido suas habilidades distintivas e obtido sucesso com o produto. Definida por Downs (1967) como Estágio do Crescimento Rápido e por Lyden (1975), de Segunda Etapa. A ênfase é alcançar rapidez no crescimento das vendas e acumular recursos para obter vantagens. Em geral, existe o estabelecimento de uma estrutura funcional, com pouca delegação de autoridade a gerentes e formalização de procedimentos (Miller \& Friesen, 1984).

A fase de maturidade tem como característica a estabilização do nível de vendas, decrescimento do nível de inovação e o estabelecimento de uma estrutura organizacional mais burocrática. Nesta etapa, as metas tornam-se funcionalmente homogêneas e eficientes. Quinn e Cameron (1983) sugerem a ideia da fase de formalização e controle, por Scott (1971) como Estágio 2; Greiner (1972) a define como Estágio de Direção; Katz e Kahn (1978), como Fase da Organização Estável (Miller \& Friesen, 1984).

A fase do renascimento equivale à fase de formação de estrutura de Quinn e Cameron (1983), a terceira fase de Scott e à fase de coordenação de Greiner (1972). Nesta fase, ocorre a diversificação e expansão do produto e do mercado. As empresas adotam estrutura dividida a fim de lidar com mercados mais complexos e heterogêneos. Há ênfase em controles mais sofisticados e sistemas de planejamento (Miller \& Friesen, 1984).

A fase final, ou o declínio, tem como perfil a estagnação no mercado, queda da rentabilidade em virtude dos desafios externos e da falta de inovação, levando ao declínio das empresas. Downs (1967) a define como Fase da Desaceleração e Lyden (1975) e Kimberly e Miles (1980), como Quarta Fase (Miller \& Friesen, 1984).

Pesquisas na área da Contabilidade Gerencial têm utilizado os modelos de ciclo de vida organizacional para relacionar com os instrumentos da Contabilidade Gerencial. Abatecola (2013) discorre sobre quais os fatores chaves para a sobrevivência ou fracasso das organizações podem estar associados a diferentes estágios do ciclo de vida organizacional, com ênfase sobre adaptação organizacional.

Cunha, Klann e Lavarda (2013) analisaram os artigos sobre a abordagem do ciclo de vida organizacional em nível internacional, levantando os principais tópicos associados com os Controles Gerenciais. Cunha, Klann e Lavarda (2013, p. 184) observaram nos artigos a busca da relação do ciclo de vida organizacional com diversos aspectos, como:

a) suas implicações na resposta do mercado de ações para as medidas de desempenho contábil;

b) seu efeito sobre práticas de Controles Gerenciais nas empresas de rápido crescimento e caracterizadas pela intensidade de aplicação de recursos em pesquisa e desenvolvimento;

c) sua influência com variáveis condicionais sobre o Sistema de Controle Gerencial em organizações de serviços;

d) como o estágio do ciclo de vida organizacional e a existência de investidores de capital de risco na empresa afetam o uso de Sistemas de Controle Gerencial, como plano de negócios, orçamento e técnicas de controle gerencial;

e) se o uso do sistema de custeio $\mathrm{ABC}$ difere entre as empresas em diferentes estágios do ciclo de vida organizacional; e

f) a estrutura da Contabilidade Gerencial e sistemas de controle nos estágios de crescimento e renascimento (Cunha et al., 2013).

Neste estudo, analisa-se o ciclo de vida organizacional com o processo de planejamento nas suas três modalidades: Planejamento Estratégico, Orçamento e Controle Orçamentário. 


\section{Contabilidade Gerencial e Planejamento}

Desde seu surgimento, a Contabilidade é uma das ferramentas que visa esclarecer, de forma objetiva, os atos e fatos que ocorreram no patrimônio das organizações, com o intuito de suprir as necessidades de informação. Pode-se dizer que a Contabilidade instituiu como uma grande ferramenta gerencial, considerada instrumento de relevância na geração de informações, utilizando-se dos princípios e das técnicas contábeis necessárias para atingir a sua finalidade. A Contabilidade Gerencial é de fundamental importância, pois permite a implementação e o controle do Planejamento Estratégico (Fezatti, Guerreiro, Aguiar \& Gouvêa, 2007).

Os relatórios da Contabilidade Gerencial abarcam os diferentes níveis hierárquicos e funcionam como ferramentas importantes para tomadas de decisões e acabam influenciando o processo de Planejamento Estratégico empresarial e o orçamento.

As mudanças que a Contabilidade Gerencial sofreu nas últimas décadas a tornou uma das principais ferramentas da gestão empresarial. Fazer uso de uma estratégia de desenvolvimento implica não somente conhecer a natureza de um negócio, mas também utilizar a informação adequada para a tomada de decisões que pode trazer benefícios tanto à empresa como seus acionistas, colaboradores, fornecedores e clientes (Barros, 2008).

Barros (2008) define a Contabilidade Gerencial como um dos recursos mais importantes para subsidiar a administração de uma empresa, em que os seus relatórios alcançam todos os níveis hierárquicos e funcionam como ferramentas indispensáveis nas tomadas de decisões, influenciando fortemente no processo de planejamento e no orçamento. A partir da Contabilidade Gerencial, é possível a implementação e o controle do Planejamento Estratégico nas organizações (Frezatti et al., 2007).

\subsection{Planejamento estratégico}

Com o desenvolvimento de técnicas e processos administrativos, as decisões que porventura precisam ser tomadas terão um embasamento mais assertivo. Lunkes (2008) comenta que o planejamento evoluiu através dos tempos no qual precisou se adaptar às novas condições e exigências do mercado.

O Planejamento Estratégico está relacionado com os objetivos de longo prazo e com estratégias e ações para alcançá-los, que interferem em todas as áreas organizacionais. É um processo administrativo que proporciona sustentação metodológica para o estabelecimento do melhor rumo a ser tomado pela empresa, visando otimizar o grau de interação com fatores externos e atuando de forma diferenciada (Oliveira, 2010).

Assim, o Planejamento Estratégico pode ser entendido como o processo pelo qual se tomam as decisões do caminho que a empresa deverá seguir nos próximos anos. Dessa forma, o Planejamento Estratégico é definido para períodos longos de tempo e busca analisar o ambiente interno e externo a fim de definir o rumo a ser tomado pela empresa. Lunkes (2008) afirma que o Planejamento Estratégico é definido para períodos de cinco ou mais anos. O autor destaca ainda quatro características do Planejamento Estratégico: abrange informações qualitativas, decide para onde a empresa vai, avalia o ambiente dentro do qual ela irá operar e desenvolve estratégias para alcançar o objetivo pretendido.

Segundo Frezatti (2007) os elementos componentes do Planejamento Estratégico são: a visão, a missão, objetivos de longo prazo, análise do ambiente externo e interno, estabelecimento de estratégias, projetos e planos de longo prazo. A visão representa a imagem que a organização tem e o que projeta para o futuro, enquanto que a missão representa a razão da existência da organização justificando seu papel perante a sociedade.

A análise externa serve para detectar ameaças ou oportunidades no ambiente externo. Oportunidade é uma força ambiental incontrolável pela empresa, que pode favorecer a sua ação estratégica, desde que seja identificada e aproveitada de modo satisfatório. A ameaça também pode ser definida como uma força ambiental incontrolável, mas que pode prejudicar a ação estratégica da empresa. Enquanto a análise externa é executada, deve-se atentar para o cenário político, econômico, fiscal e social, pois podem afetar 
de forma direta ou indireta o negócio. Por outro lado, a análise interna volta-se para analisar pontos fortes e fracos da organização, buscando identificar necessidades de recursos requeridos para que a empresa alcance seus objetivos (Frezatti, 2007).

A estratégia compreende as ações que deverão ser executadas. É a maneira pela qual uma empresa quer alcançar seus objetivos em um ambiente marcado pela competitividade e que está em constantes mudanças. Os planos de longo prazo complementam o modelo de Planejamento Estratégico proposto por Frezatti (2007). Deve ser implementado a partir do orçamento e acompanhado pelo controle orçamentário e conter a avaliação financeira de todo plano estratégico, por meio de demonstrações de resultado, balanços e fluxos de caixa para o período de longo prazo. Além disso, o Planejamento Estratégico depende de instrumentos táticos que transformam as decisões de longo prazo em algo concreto; constitui-se de uma ferramenta para implementar as decisões do plano estratégico, permitindo focar e identificar suas ações.

\subsection{Orçamento}

O orçamento é um importante instrumento para o planejamento das empresas. As práticas orçamentárias evoluíram ao longo do tempo principalmente em função da utilização deste como instrumento de políticas governamentais. O orçamento é o artefato gerencial mais utilizado nas organizações e tornou-se o elemento central de muitos sistemas de gestão usados pelas empresas, pois permite um gerenciamento central (Bornia \& Lunkes, 2007).

$\mathrm{O}$ orçamento representa para as empresas um instrumento importante para o planejamento e controle de suas atividades em curto prazo (Horngrem, Sundem, \& Stratton, 2004; Anthony \& Govindarajan, 2006; Atkinson, Banker, Kaplan, \& Young, 2008). Constitui-se em um plano financeiro para implementar a estratégia da empresa, durante um determinado período (Frezatti, 2007).

Assim, o orçamento constitui-se em uma ferramenta que irá implantar o programa aprovado pelo Planejamento Estratégico, traduzindo os planos de longo prazo do negócio em um plano operacional anual (Lunkes, 2008). De acordo com Atkinson et al. (2008), o orçamento é um meio de a empresa comunicar suas metas de curto prazo a todos os seus membros. O orçamento também coordena muitas atividades da empresa, como, por exemplo, as atividades de compras, vendas, produção e administrativas, e auxilia na identificação de problemas de coordenação dessas atividades.

Horngrem et al. (2004) comentam que muitas pessoas visualizam o orçamento como um limitador dos gastos. Entretanto, as empresas o utilizam não apenas como um limitador dos gastos, mas também como um meio para focalizar a atenção nas suas operações e finanças.

\subsection{Controle Orçamentário}

Frezatti (2007) comenta que planejar sem controlar é uma falácia e desperdício de tempo e energia. Significa que energia foi despendida pelos gestores decidindo o futuro, sem que se possa saber se os objetivos estão sendo atingidos. O controle é fundamental para o entendimento do grau de desempenho atingido e quão próximo o resultado almejado se situou em relação ao planejado.

O controle é importante para a empresa saber o quanto cumpriu com o que foi planejado. Assim, será possível analisar se atingiu, ou não, os objetivos e metas traçados no Planejamento Estratégico. $\mathrm{O}$ controle orçamentário proporciona o feedback para orientar os gestores sobre seu desempenho e reorientar as suas atividades e prioridades, alimentando o processo de planejamento (Frezatti et al., 2010).

Lau (1999) comenta que o planejamento eficaz garante que as metas sejam cuidadosamente escolhidas, e o controle eficaz garante que o plano de ação escolhido seja implementado adequadamente, garantindo assim que os objetivos sejam atingidos. Planejamento sem o controle complementar será malsucedido. Da mesma forma, os controles não são significativos sem um apropriado planejamento. 


\section{Método e Técnicas da Pesquisa}

Nesta seção, apresentam-se o método e os procedimentos utilizados para realização da pesquisa. Descreve-se sobre o delineamento da pesquisa, a definição da população e amostra, instrumento da pesquisa e a forma de coleta e análise dos dados.

\subsection{Delineamento da Pesquisa}

Quanto à tipologia da pesquisa, este estudo é delineado a partir de três abordagens referentes: a) ao problema de pesquisa; b) aos objetivos; $c$ ) aos procedimentos. A presente pesquisa foi desenvolvida por meio de uma pesquisa descritiva (quanto aos objetivos) com abordagem quantitativa em relação ao problema.

Conforme Cervo e Bervian (1996, p. 66), "a pesquisa descritiva observa, analisa e correlaciona fatos ou fenômenos (variáveis) sem manipulá-los". Afirmam ainda que a pesquisa descritiva "procura descobrir, com a previsão possível, a frequência com que um fenômeno ocorre, sua relação e conexão com outros, sua natureza e características". Conforme Hair, Babin, Money e Samouel (2005), recomenda-se utilizar da abordagem quantitativa em procedimentos descritivos, nos quais se procura descobrir e classificar a relação entre variáveis, buscar a validação de fatos, encontrar estimativas e relacionamentos e testar hipóteses.

Este estudo caracteriza-se como descritivo com abordagem quantitativa, uma vez que procura identificar e descrever os estágios do ciclo de vida organizacional pautados no modelo de Miller e Friesen (1984) das empresas prestadoras de serviços contábeis do Estado de Santa Catarina. Ainda como característica de um estudo descritivo, esta pesquisa procura identificar o estabelecimento de relações entre variáveis, como a relação dos diferentes estágios do ciclo de vida organizacional com o processo de planejamento das empresas prestadoras de serviços contábeis.

No que concerne aos procedimentos, caracteriza-se como pesquisa de levantamento ou survey. Gil (2002, p. 50) comenta que neste tipo de pesquisa "procede-se à solicitação de informações a um grupo significativo de pessoas acerca do problema estudado, para, em seguida, [...] obterem-se as conclusões correspondentes aos dados coletados". Desse modo, neste estudo foi aplicado um questionário a uma determinada população. A população desta pesquisa compreendeu as 2.079 empresas prestadoras de serviços contábeis do Estado de Santa Catarina, que estavam inscritas no Conselho Regional de Contabilidade [CRCSC] no ano de 2012.

A coleta dos dados foi realizada via questionário eletrônico elaborado no Google Docs. Entrouse em contato por e-mail e telefone com o CRCSC para apresentação da pesquisa e para solicitar que o Conselho encaminhasse o questionário aos proprietários das empresas prestadoras de serviços contábeis. O questionário foi enviado para todas as empresas prestadoras de serviços contábeis de Santa Catarina durante a segunda quinzena do mês de março de 2012 até abril, sendo que se obtiveram 116 respostas válidas para análise, representando uma amostra composta por 5,6\% da população.

\subsection{Instrumento da Pesquisa}

Os instrumentos de pesquisa são as técnicas ou processos utilizados para coleta de dados. Marconi e Lakatos (2005) explicam que são vários os procedimentos para a realização da coleta de dados, que modificam conforme as circunstâncias ou com o tipo de investigação. As técnicas de pesquisa podem ser: documental, observação, entrevista, questionários, análise de conteúdo, entre outras. No caso desta pesquisa, o instrumento de pesquisa adotado é o questionário. 
O questionário contém dois blocos, sendo que o primeiro abarca vinte questões para identificar em qual estágio do ciclo de vida as organizações se encontram. Para tanto, adaptou-se o questionário utilizado por Frezatti et al. (2010), utilizando uma escala ordinal crescente de 1 a 5, em que 1 = Discordo Totalmente, $2=$ Discordo, 3 = Indiferente, $4=$ Concordo, 5 = Concordo Totalmente. O Quadro 2 evidencia as assertivas utilizadas no questionário para identificação do estágio de ciclo de vida das empresas.

\begin{tabular}{|c|c|c|}
\hline Numeração & Indicadores para mensuração do estagio do ciclo de vida & Ciclo de Vida Organizacional \\
\hline 1 & $\begin{array}{l}\text { Como organização, somos menores do que a maioria dos nossos } \\
\text { concorrentes. }\end{array}$ & Nascimento \\
\hline 2 & $\begin{array}{l}\text { Como empresa, somos maiores do que a maioria dos nossos } \\
\text { concorrentes, mas não tão grande como deveríamos ser. }\end{array}$ & Maturidade \\
\hline 3 & Somos uma organização com sócios, gerentes e coordenadores. & Rejuvenescimento \\
\hline 4 & $\begin{array}{l}\text { O poder decisório da organização está nas mãos do fundador da } \\
\text { empresa. }\end{array}$ & Nascimento \\
\hline 5 & $\begin{array}{l}\text { O poder decisório da organização é dividido entre muitos sócios, } \\
\text { gerentes e coordenadores. }\end{array}$ & Crescimento \\
\hline 6 & $\begin{array}{l}\text { O poder decisório da organização está nas mãos de um grande } \\
\text { número de sócios. }\end{array}$ & Maturidade \\
\hline 7 & A estrutura organizacional da empresa pode ser considerada simples. & Nascimento \\
\hline 8 & $\begin{array}{l}\text { A estrutura organizacional da empresa está baseada na visão } \\
\text { funcional. }\end{array}$ & Maturidade \\
\hline 9 & O estilo de decisão leva em conta a inovação e o risco. & Rejuvenescimento \\
\hline 10 & $\begin{array}{l}\text { A estrutura organizacional da empresa é divisional com sofisticado } \\
\text { sistema de controle. }\end{array}$ & Rejuvenescimento \\
\hline 11 & $\begin{array}{l}\text { A estrutura organizacional da empresa é centralizada com poucos } \\
\text { sistemas de controle. }\end{array}$ & Declínio \\
\hline 12 & $\begin{array}{l}\text { Na organização temos várias especializações (contadores, advogados, } \\
\text { administradores, etc.) e, com isso nos tornamos diferenciados. }\end{array}$ & Crescimento \\
\hline 13 & $\begin{array}{l}\text { O processamento de informações na organização pode ser descrito } \\
\text { como monitorador de desempenho e facilitador de comunicação } \\
\text { entre os departamentos. }\end{array}$ & Crescimento \\
\hline 14 & $\begin{array}{l}\text { O processamento de informações na organização pode ser descrito } \\
\text { como simples, no estilo "boca a boca". }\end{array}$ & Nascimento \\
\hline 15 & $\begin{array}{l}\text { O processamento de informações é sofisticado e necessário para a } \\
\text { produção eficiente e para atingir os resultados requeridos. }\end{array}$ & Maturidade \\
\hline 16 & $\begin{array}{l}\text { O processamento de informações é sofisticado e utilizado na } \\
\text { coordenação de diversas atividades para melhor servir aos clientes de } \\
\text { diferentes portes e segmentos. }\end{array}$ & Rejuvenescimento \\
\hline 17 & O processamento de informações não é muito sofisticado. & Declínio \\
\hline 18 & O processamento de informações é utilizado de maneira não plena. & Declínio \\
\hline 19 & $\begin{array}{l}\text { O processo decisório é centralizado na alta administração, } \\
\text { considerado não muito complexo. }\end{array}$ & Declínio \\
\hline 20 & $\begin{array}{l}\text { As decisões se tornam menos dependentes das opiniões dos sócios e } \\
\text { são mais centradas entre os gerentes e coordenadores. }\end{array}$ & Crescimento \\
\hline
\end{tabular}

Quadro 2. Indicadores para mensuração do estágio de ciclo de vida

Fonte: adaptado de Frezatti et al. (2010, p. 391)

Observa-se no Quadro 2 as assertivas utilizadas para identificar o estágio do ciclo de vida das empresas prestadoras de serviços contábeis. São considerados cinco possíveis estágios: nascimento, crescimento, maturidade, rejuvenescimento e declínio. 
O segundo bloco do instrumento de pesquisa é constituído por vinte e três perguntas, que tem por finalidade verificar os artefatos de planejamento utilizados pelas empresas prestadoras de serviços contábeis. Neste caso, utilizou-se uma escala binária, em que 1 representava "sim" e 0 representava "não". Para alcançar esse objetivo, adaptou-se o constructo utilizado por Frezatti et al. (2010), podendo ser visualizado no Quadro 3.

\begin{tabular}{|c|c|}
\hline Artefatos considerados & Itens para mensuração dos artefatos \\
\hline \multirow{9}{*}{ Planejamento Estratégico } & Visão \\
\hline & Missão \\
\hline & Objetivo de longo prazo \\
\hline & Análise de cenários externos \\
\hline & Análise de cenários internos \\
\hline & Estratégias \\
\hline & Plano de investimento \\
\hline & Planos operacionais de longo prazo \\
\hline & BSC (Balanced Scorecard) como etapa de controle \\
\hline \multirow{7}{*}{ Orçamento } & Premissas econômico-financeiras \\
\hline & Plano de marketing \\
\hline & Plano de $\mathrm{RH}$ \\
\hline & Plano de investimento no ativo permanente \\
\hline & Balanço Patrimonial projetado \\
\hline & Balanço do Resultado do Exercício projetado \\
\hline & Fluxo de Caixa projetado \\
\hline \multirow{7}{*}{ Controle Orçamentário } & Acompanha todas as linhas do balanço, confrontando o orçado com o realizado. \\
\hline & $\begin{array}{l}\text { Acompanha todas as linhas da demonstração de resultado, confrontando o orçado com } \\
\text { o realizado. }\end{array}$ \\
\hline & Acompanha todas as linhas do fluxo de caixa, confrontando o orçado com o realizado. \\
\hline & $\begin{array}{l}\text { Acompanha todas as linhas de custos e despesas, confrontando o orçado com o } \\
\text { realizado. }\end{array}$ \\
\hline & Acompanha o Valor Econômico Agregado (EVA), confrontando o orçado com o realizado. \\
\hline & Acompanha os indicadores-chave, confrontando o previsto com o realizado. \\
\hline & Acompanha o valor da empresa. \\
\hline
\end{tabular}

Quadro 3. Indicadores para mensuração dos artefatos de planejamento

Fonte: adaptado de Frezatti et al. (2010, p. 392)

Desse modo, observa-se que o instrumento de pesquisa teve o intuito de identificar os estágios de ciclo de vida das organizações, bem como os artefatos utilizados no processo de planejamento. Ao todo, foram adaptadas 43 questões do estudo de Frezatti et al. (2010), além de conter características das empresas e do perfil dos respondentes.

\subsection{Coleta e Análise dos Dados}

De posse das 116 respostas, procedeu-se à tabulação dos dados em uma planilha eletrônica para em seguida iniciar a análise dos dados. No primeiro bloco do questionário, foram calculadas as pontuações totais de cada uma das empresas. Assim, as empresas prestadoras de serviços contábeis foram classificadas no estágio que obtiveram maior pontuação, uma vez que a escala utilizada foi definida como crescente. 
No entanto, foram observados alguns casos em que houve empate na pontuação, e as empresas tiveram mais de uma classificação, ou seja, obtiveram a mesma pontuação em estágios distintos de ciclo de vida. Para contornar o problema do empate na classificação, fez-se o uso da análise discriminante.

A análise discriminante "auxilia a identificar quais variáveis que diferenciam os grupos e quantas dessas variáveis são necessárias para obter a melhor classificação dos indivíduos de uma determinada população" (Mário, 2011, p. 234). Em seguida, no segundo bloco, iniciou-se a análise do nível de utilização dos artefatos do planejamento das empresas analisadas. Por fim, analisou-se a correlação entre o ciclo de vida organizacional e o nível de planejamento das empresas que fizeram parte da pesquisa.

\section{Descrição e Análise dos Resultados}

\subsection{Estágios do ciclo de vida organizacional das empresas prestadoras de serviços contábeis}

Primeiramente, realizou-se a classificação das empresas nos diferentes estágios de ciclo de vida organizacional, levando em consideração as respostas obtidas nas assertivas. Dessa forma, as empresas da amostra apresentaram características de todos os ciclos. No entanto, algumas revelaram características mais marcantes em um ciclo específico, enquanto outras apresentaram fortes características de dois ou três ciclos.

No caso de ocorrer a classificação em mais de um ciclo, utilizou-se como critério de desempate a escolha do menor ciclo. Por exemplo, a empresa "E3" apresentou fortes características em dois ciclos: crescimento e rejuvenescimento. Neste caso, a empresa "E3" ficou classificada em crescimento. A Tabela 1 demonstra a quantidade de empresas classificadas em cada estágio de ciclo de vida organizacional, utilizando-se do modelo de Miller e Friesen (1984).

Tabela 1

Classificação dos estágios de ciclo de vida organizacional

\begin{tabular}{|c|c|c|}
\hline Estágio & Quantidade de empresas & Frequência relativa (\%) \\
\hline Nascimento & 49 & 42,24 \\
\hline Crescimento & 16 & 13,79 \\
\hline Maturidade & 9 & 7,76 \\
\hline Rejuvenescimento & 28 & 24,14 \\
\hline Declínio & 14 & 12,07 \\
\hline Total & 116 & 100,00 \\
\hline
\end{tabular}

Fonte: dados da pesquisa

Observa-se que a maior parte das empresas foram classificadas no estágio de nascimento, representando $42,24 \%$, seguidas do estágio de rejuvenescimento, com $24,24 \%$. Para confirmar a classificação nos estágios de ciclo de vida, utilizou-se a técnica multivariada denominada análise discriminante. Segundo Mário (2011, p. 233), “a análise discriminante é uma das técnicas que se desenvolveram para auxiliar o pesquisador na classificação ou pré-classificação de um elemento de um determinado grupo, economizando tempo e esforços". Para que a técnica possa ser validada, ela precisa apresentar uma característica que consiste na utilização de um conjunto de informações obtidas via variáveis independentes (quantitativa, métrica) para, dessa forma, extrair um valor de uma variável dependente (natureza qualitativa, não métrica) que possibilite classificá-las de modo adequado.

$\mathrm{Na}$ análise discriminante, para garantir que os resultados da pesquisa sejam consistentes, se faz necessário testar a alguns pressupostos, ou seja, algumas condições devem ser atendidas. Esses pressupostos são: normalidade multivariada, linearidade, ausência de outlier, ausência de multicolinearidade. 
A normalidade multivariada das variáveis representa a condição/pressuposto de que a combinação linear entre as variáveis das funções deve seguir uma distribuição normal. O não atendimento a essa condição pode comprometer a validade do modelo, por que esses modelos utilizam testes de significância que as variáveis devem seguir em uma distribuição normal.

Para testar a normalidade multivariada das variáveis, aplicou-se o teste One-Sample KolmogorovSmirnov no SPSS, com nível de significância de 5\%. Considerando que a hipótese nula pressupõe que os dados seguem uma distribuição normal e a hipótese alternativa pressupõe que os dados não seguem uma distribuição normal, os resultados do teste são expressos na Tabela 2.

Tabela 2

Resultados do teste de normalidade dos dados

\begin{tabular}{llrrrrr} 
& & Nasc & Cresc & Matur & Rejuv & Decli \\
\hline $\mathrm{N}$ & & 116 & 116 & 116 & 116 & 116 \\
\hline Normal Parameters (a,b) & Mean & 12.8534 & 11.4397 & 11.7672 & 12.8534 & 11.9569 \\
\hline & Std. Deviation & 3.28171 & 3.49481 & 2.54817 & 3.38861 & 3.34246 \\
\hline Most Extreme Differences & Absolute & .138 & .087 & .111 & .091 & .117 \\
\hline & Positive & .059 & .087 & .110 & .091 & .087 \\
\hline & Negative & -.138 & -.071 & -.111 & -.090 & -.117 \\
\hline Kolmogorov-Smirnov Z & & 1.492 & .942 & 1.198 & .978 & 1.262 \\
\hline Asymp. Sig. (2-tailed) & & .023 & .337 & .113 & .294 & .083 \\
\hline
\end{tabular}

Fonte: dados da pesquisa

Nota-se que não há evidência para rejeitar a hipótese nula para as variáveis: crescimento, maturidade, rejuvenescimento e declínio (sig.>0,05). Dessa forma, os dados estão distribuídos de forma normal, atendendo ao primeiro pressuposto da técnica de análise discriminante, exceto a variável Nascimento, que não apresentou distribuição normal (sig.0,023<0,05).

De acordo com Mário (2011), um simples teste para comprovar a normalidade dos dados é verificar o histograma. Um histograma é a representação gráfica de uma variável e retrata os valores dos dados dentro de uma categoria dos dados. Assim, observando o histograma resultante das ocorrências da variável Nascimento, verifica-se que este representa uma distribuição normal, ou seja, um padrão de referência utilizado nos métodos estatísticos.

Além disso, Mário (2011) argumenta que pode ser levado em consideração o Teorema do Limite Central, o qual preconiza que, apesar de não se conhecer a distribuição da população, ou ainda se esta não apresentar normalidade, as distribuições amostrais tornam-se normais se tivermos a disposição uma amostra grande o suficiente. Nesse sentido, é possível supor normalidade na variável nascimento, através da visualização do histograma e do tamanho da amostra (116 empresas).

A linearidade que corresponde a outro pressuposto a ser atendido "refere-se à combinação linear entre todas as variáveis independentes." (Mário, 2011, p. 243). Por outro lado, Hair Jr., Black, Babin, Anderson e Tatham (2009, p. 86) asseguram que "o modo mais comum de avaliar a linearidade é examinar diagramas de dispersão das variáveis e identificar qualquer padrão não linear dos dados". Dessa forma, analisando os diagramas de dispersão dos dados, ratificou-se que não existe linearidade entre as variáveis independentes, atendendo assim ao segundo pressuposto da técnica da análise discriminante.

Quanto ao terceiro pressuposto da análise discriminante, que se refere à ausência de outliers, ou seja, dados discrepantes ou muito diferentes das demais observações, utiliza-se a análise dos gráficos de caixa (Boxplot). Procedeu-se à análise e não foi constatada presença de outliers. 
Na sequência, analisa-se a não ocorrência de multicolinearidade correspondente ao quarto pressuposto. A multicolinearidade acontece quando duas ou mais variáveis independentes do modelo exibem informações parecidas, ou seja, apresentam alto grau de correlação. Uma alta correlação distorce o real efeito dos coeficientes das variáveis (dependentes e independentes) e pode prejudicar a habilidade preditiva do modelo. Para avaliar a relação entre as variáveis, utilizam-se os resultados obtidos das matrizes de covariância e correlação (Fávero, Belfiore, Silva, \& Chan, 2009). A matriz de covariância e correlação pode ser observada na Tabela 3.

Tabela 3

Matrizes de covariância e correlações

\begin{tabular}{ccccccc} 
& & Nasc & Cresc & Matur & Rejuv & Decli \\
\hline Covariance & Nasc & 5.270 & -1.293 & .035 & -.388 & 2.594 \\
\hline & Cresc & -1.293 & 6.702 & 2.150 & 3.884 & -.569 \\
\hline & Matur & .035 & 2.150 & 4.487 & 3.040 & .329 \\
\hline Correlation & Rejuv & -.388 & 3.884 & 3.040 & 6.115 & -.404 \\
\hline & Decli & 2.594 & -.569 & .329 & -.404 & 7.312 \\
\hline & Nasc & 1.000 & -.218 & .007 & -.068 & .418 \\
\hline & Cresc & -.218 & 1.000 & .392 & .607 & -.081 \\
\hline & Matur & .007 & .392 & 1.000 & .580 & .057 \\
\hline & Rejuv & -.068 & .607 & .580 & 1.000 & -.060 \\
\hline
\end{tabular}

Fonte: dados da pesquisa

O problema da multicolinearidade ocorre quando as variáveis independentes são muito correlacionadas, dificultando o desmembramento dos efeitos de cada uma delas sobre a variável dependente (Mário, 2011). Para Hair Jr et al. (2009), valores elevados (maiores ou iguais 0,90) de correlação indica presença de multicolinearidade. Analisando a Tabela 3, nota-se que não há multicolinearidade entre as variáveis e, portanto, atende-se ao quarto pressuposto da análise discriminante.

Nota-se que as características do estágio das empresas, Nascimento e Maturidade, são as que menos se relacionam (0.007). Por outro lado, as características Crescimento e Rejuvenescimento apresentam forte correlação (0.607). Por meio do teste Box's $M$, consegue-se confirmar se houve, ou não, a violação da igualdade entre as matrizes de covariância. Neste teste, a hipótese nula tem como premissa que não há diferenças significativas entre os grupos, ou seja, há homogeneidade das matrizes de variância e covariância (Fávero et al., 2009).

Analisando os resultados do teste Box’s M, verifica-se violação da premissa (sig 0.002<0.05), ou seja, as matrizes de covariância entre os grupos não são homogêneas e não foi atendido o último pressuposto.

Mário (2011) salienta que esse problema pode ser devido ao tamanho da amostra ou pela ausência da normalidade multivariada e que, apesar de as premissas terem sido violadas, o software não deixou de fornecer as demais etapas, indicando que as violações não estão impossibilitando a pesquisa.

Para finalizar, processou-se a análise discriminante com o intuito de confirmar a correta classificação das empresas quanto ao ciclo de vida organizacional. No caso das empresas que tinham sido classificadas em mais de um estágio, decidiu-se classificar no estágio menos avançado encontrado. Por exemplo, se a empresa tinha pontuação empatada para o ciclo Nascimento e Declínio, foi classificado em Nascimento. Na Tabela 4, encontram-se os resultados encontrados. 
Tabela 4

Classificação das empresas por meio da análise discriminante

\begin{tabular}{|c|c|c|c|c|c|c|c|c|}
\hline Empresa & $\begin{array}{l}\text { Actual } \\
\text { Group }\end{array}$ & $\begin{array}{l}\text { Predicted } \\
\text { Group }\end{array}$ & Empresa & $\begin{array}{l}\text { Actual } \\
\text { Group }\end{array}$ & $\begin{array}{l}\text { Predicted } \\
\text { Group }\end{array}$ & Empresa & $\begin{array}{l}\text { Actual } \\
\text { Group }\end{array}$ & $\begin{array}{l}\text { Predicted } \\
\text { Group }\end{array}$ \\
\hline 1 & 1 & 1 & 40 & 2 & 2 & 79 & 1 & 1 \\
\hline 2 & 1 & 1 & 41 & 5 & 5 & 80 & 2 & 2 \\
\hline 3 & 2 & 2 & 42 & 4 & 4 & 81 & 2 & 2 \\
\hline 4 & 5 & 5 & 43 & 1 & 1 & 82 & 4 & 4 \\
\hline 5 & 1 & 1 & 44 & 1 & 1 & 83 & 4 & 4 \\
\hline 6 & 1 & $2(* *)$ & 45 & 1 & 1 & 84 & 1 & 1 \\
\hline 7 & 4 & 4 & 46 & 1 & 1 & 85 & 4 & 4 \\
\hline 8 & 4 & 4 & 47 & 5 & 5 & 86 & 1 & 1 \\
\hline 9 & 5 & 5 & 48 & 3 & 3 & 87 & 1 & 1 \\
\hline 10 & 1 & 1 & 49 & 4 & 4 & 88 & 1 & 1 \\
\hline 11 & 4 & 4 & 50 & 2 & 2 & 89 & 4 & 4 \\
\hline 12 & 1 & 1 & 51 & 2 & 2 & 90 & 4 & 4 \\
\hline 13 & 4 & 4 & 52 & 1 & 1 & 91 & 4 & 4 \\
\hline 14 & 1 & $2(* *)$ & 53 & 1 & 1 & 92 & 1 & 1 \\
\hline 15 & 1 & 1 & 54 & 1 & 1 & 93 & 1 & 1 \\
\hline 16 & 4 & 4 & 55 & 4 & 4 & 94 & 1 & 1 \\
\hline 17 & 4 & 4 & 56 & 1 & $5(* *)$ & 95 & 2 & 2 \\
\hline 18 & 1 & 1 & 57 & 3 & 3 & 96 & 5 & 5 \\
\hline 19 & 1 & 1 & 58 & 2 & 2 & 97 & 5 & 5 \\
\hline 20 & 1 & 1 & 59 & 2 & 2 & 98 & 3 & 3 \\
\hline 21 & 1 & 1 & 60 & 3 & 3 & 99 & 1 & 1 \\
\hline 22 & 5 & $3(* *)$ & 61 & 1 & 1 & 100 & 4 & 4 \\
\hline 23 & 1 & $5(* *)$ & 62 & 4 & 4 & 101 & 5 & 5 \\
\hline 24 & 1 & 1 & 63 & 3 & 3 & 102 & 1 & 1 \\
\hline 25 & 1 & 1 & 64 & 4 & $2(* *)$ & 103 & 1 & 1 \\
\hline 26 & 1 & 1 & 65 & 1 & 1 & 104 & 1 & 1 \\
\hline 27 & 5 & 5 & 66 & 5 & 5 & 105 & 4 & 4 \\
\hline 28 & 1 & 1 & 67 & 4 & 4 & 106 & 3 & 3 \\
\hline 29 & 2 & 2 & 68 & 2 & 2 & 107 & 1 & $5(* *)$ \\
\hline 30 & 5 & 5 & 69 & 4 & 4 & 108 & 4 & 4 \\
\hline 31 & 1 & 1 & 70 & 4 & 4 & 109 & 3 & 3 \\
\hline 32 & 4 & 4 & 71 & 1 & 1 & 110 & 3 & 3 \\
\hline 33 & 4 & $3(* *)$ & 72 & 5 & 5 & 111 & 4 & 4 \\
\hline 34 & 1 & 1 & 73 & 2 & 2 & 112 & 2 & 2 \\
\hline 35 & 1 & 1 & 74 & 2 & 2 & 113 & 1 & 1 \\
\hline 36 & 1 & 1 & 75 & 5 & 5 & 114 & 1 & 1 \\
\hline 37 & 4 & 4 & 76 & 3 & 3 & 115 & 5 & 5 \\
\hline 38 & 1 & 1 & 77 & 2 & 2 & 116 & 2 & 2 \\
\hline 39 & 4 & 4 & 78 & 1 & 1 & & & \\
\hline
\end{tabular}

Fonte: dados da pesquisa 
$\mathrm{Na}$ Tabela 4, na coluna actual group, são apresentados os estágios de ciclo de vida organizacional em que as empresas foram inicialmente classificadas, enquanto na coluna predicted group são apresentados os estágios em que as empresas foram novamente classificadas pela análise discriminante. O número 1 equivale ao Nascimento, o 2 ao Crescimento, o 3 À Maturidade, o 4 Ao Rejuvenescimento e o 5 ao Declínio.

Inicialmente, as empresas 6 e 14 tinham sido classificadas no estágio de Nascimento, no entanto, a análise discriminante as classificou no estágio de Crescimento. As empresas 23, 56 e 107 tinham sido classificadas no estágio de Nascimento, mas a classificação realizada pela técnica estatística aponta para o estágio de declínio. Por outro lado, a empresa 22, que tinha sido classificada no estágio de declínio, recebeu nova classificação, passando para o estágio de Maturidade. Ainda as empresas 33 e 64, que estavam no estágio de Rejuvenescimento, passaram para o estágio de Maturidade e Crescimento, respectivamente.

A Tabela 5, apresenta a quantidade de empresas classificadas por estágio de ciclo de vida após a aplicação da análise discriminante.

Tabela 5

Quantidade de empresas por estágio após aplicação da análise discriminante

\begin{tabular}{|c|c|c|}
\hline Estágio & Quantidade de empresas & Frequência relativa (\%) \\
\hline Nascimento & 46 & 39,66 \\
\hline Crescimento & 17 & 14,66 \\
\hline Maturidade & 11 & 9,48 \\
\hline Rejuvenescimento & 26 & 22,41 \\
\hline Declínio & 16 & 13,79 \\
\hline Total & 116 & 100,00 \\
\hline
\end{tabular}

Fonte: dados da pesquisa

Ao comparar a Tabela 5 com os resultados apresentados na Tabela 1, nota-se que a quantidade de empresas no estágio de Nascimento e Rejuvenescimento diminuiu, enquanto que a quantidade de empresas no nível de Crescimento, Maturidade e Declínio aumentou. Entretanto, neste estudo não houve alterações significativas em função da aplicação da análise discriminante. Observa-se que as empresas prestadoras de serviços contábeis estão classificadas em distintos estágios de ciclo de vida organizacional, com predominância no estágio de Nascimento e Rejuvenescimento.

\subsection{Nível de planejamento das empresas pesquisadas}

Com o intuito de se fazer uma avaliação das variáveis referentes ao perfil do planejamento das empresas prestadoras de serviços contábeis (Planejamento Estratégico, Orçamento e Controle Orçamentário), utilizouse uma escala binária, em que 1 representava "sim" e 0 representava "não". As variáveis dos itens utilizados para mensurar os artefatos de planejamento foram apresentadas no Quadro 3.

Salienta-se que foram considerados 9 itens para Planejamento Estratégico, 7 itens para Orçamento e para Controle Orçamentário. Assim, a quantidade mínima de pontos que cada empresa poderia computar por variável seria 0 (se não utilizasse o artefato), e a quantia máxima seria 9 para Planejamento Estratégico e 7 para Orçamento e para Controle Orçamentário. Procedeu-se à soma desses itens e calcularam-se as médias aritméticas e a proporção. Os resultados apresentam-se evidenciados na Tabela 6 . 
Tabela 6

Nível de utilização dos artefatos de planejamento

\begin{tabular}{lccc}
\multicolumn{1}{c}{ Artefatos } & Planejamento estratégico & Orçamento & Controle orçamentário \\
\hline Pontuação máxima & 9 & 7 & 7 \\
\hline Média & 5,44 & 3,58 & 3,33 \\
\hline Proporção & $60,5 \%$ & $51,1 \%$ & $47,6 \%$ \\
\hline
\end{tabular}

Fonte: dados da pesquisa

Analisando-se a proporção da média e a pontuação máxima que cada empresa poderia atingir, notase que os artefatos de planejamento mais utilizados são o Planejamento Estratégico (60,5\%), seguido do Orçamento (51,1\%) e do Controle Orçamentário (47,6\%).

Dos três artefatos pesquisados, o Planejamento Estratégico foi o mais significativo, apresentando $60,5 \%$ da pontuação máxima, evidenciando que as empresas atribuem certa consideração a esta ferramenta. Salientase que essas três modalidades devem ser utilizadas em conjunto. Conforme apresentado no Referencial Teórico, Frezatti (2007) menciona que o controle é importante para a empresa saber o quanto cumpriu com o que foi planejado. $O$ autor enfatiza que planejar sem controlar é uma falácia e desperdício de tempo e energia. Portanto, o Planejamento Estratégico deve ser utilizado concomitantemente como o Orçamento e o Controle Orçamentário.

Após analisar os artefatos de planejamento utilizados pelas empresas e os estágios do ciclo de vida separadamente, procedeu-se ao cálculo das correlações entre esses artefatos e os estágios do ciclo de vida organizacional das empresas que fazem parte da presente pesquisa.

\subsection{Correlação entre o ciclo de vida organizacional e o nível de planejamento das empresas pesquisadas}

A Tabela 7 apresenta as correlações entre os estágios de ciclo de vida e os artefatos utilizados pelas prestadoras de serviços contábeis.

Tabela 7

Correlação entre o ciclo de vida organizacional e os artefatos de planejamento utilizados

\begin{tabular}{|c|c|c|c|c|c|c|c|c|c|}
\hline & \multirow[b]{2}{*}{ Nasc } & & & & & & & \\
\hline & & & Cresc & Matur & Rejuv & Declín & Planej & Orçam & Contr \\
\hline \multirow[t]{2}{*}{ Nasc } & Pears Correl. & 1 & $-.522(* *)$ & $-.319\left(^{* *}\right)$ & $-.445(* *)$ & $.531\left(^{* *}\right)$ & $-.384(* *)$ & $-.344(* *)$ & $\left.-.281{ }^{(* *}\right)$ \\
\hline & Sig(2-tailed) & & .000 & .000 & .000 & .000 & .000 & .000 & .002 \\
\hline \multirow[t]{2}{*}{ Cresc } & Pears Correl. & $-.522(* \star)$ & 1 & $.494(* *)$ & $.674(* *)$ & $-.394(* *)$ & $.409\left(^{* *}\right)$ & $.342(* *)$ & $.263(* *)$ \\
\hline & Sig(2-tailed) & .000 & & .000 & .000 & .000 & .000 & .000 & .004 \\
\hline \multirow[t]{2}{*}{ Matur } & Pears Correl. & $-.319\left(^{* *}\right)$ & $.494(* *)$ & 1 & $.646(* \star)$ & $-.255(* *)$ & $.356(* \star)$ & $.409(* *)$ & $.297\left(^{* *}\right)$ \\
\hline & Sig(2-tailed) & .000 & .000 & & .000 & .006 & .000 & .000 & .001 \\
\hline \multirow[t]{2}{*}{ Rejuv } & Pears Correl. & $-.445(* \star)$ & $.674\left(^{* *}\right)$ & $.646\left(^{* *}\right)$ & 1 & $-.405(* *)$ & $.407\left(^{* *}\right)$ & $.340(* *)$ & $.284(* *)$ \\
\hline & Sig(2-tailed) & .000 & .000 & .000 & & .000 & .000 & .000 & .002 \\
\hline \multirow[t]{2}{*}{ Declin } & Pears Correl. & $.531(* *)$ & $-.394(* *)$ & $-.255(* *)$ & $-.405(* *)$ & 1 & $-.335(* *)$ & $-.281(* *)$ & $-.253(* *)$ \\
\hline & Sig(2-tailed) & .000 & .000 & .006 & .000 & & .000 & .002 & .006 \\
\hline \multirow[t]{2}{*}{ Planej } & Pears Correl. & $-.384(* *)$ & $.409(* *)$ & $.356(* \star)$ & $.407\left(^{\star \star}\right)$ & $-.335(* *)$ & 1 & $.736(* *)$ & $.633(* *)$ \\
\hline & Sig(2-tailed) & .000 & .000 & .000 & .000 & .000 & & .000 & .000 \\
\hline \multirow[t]{2}{*}{ Orçam } & Pears Correl. & $-.344(* *)$ & $.342(* *)$ & $.409\left(^{* *}\right)$ & $.340\left(^{* *}\right)$ & $-.281(* *)$ & $.736\left(^{* *}\right)$ & 1 & $.758\left(^{* *}\right)$ \\
\hline & Sig(2-tailed) & .000 & .000 & .000 & .000 & .002 & .000 & & .000 \\
\hline \multirow[t]{2}{*}{ Contr } & Pears Correl. & $-.281(* *)$ & $.263(* *)$ & $.297(* *)$ & $.284(* *)$ & $-.253(* *)$ & $.633(* *)$ & $.758(\star *)$ & 1 \\
\hline & Sig(2-tailed) & .002 & .004 & .001 & .002 & .006 & .000 & .000 & \\
\hline
\end{tabular}

Fonte: dados da pesquisa 
As siglas, nasc, cresc, matur, rejuv e declin representam as variáveis do ciclo de vida organizacional, e as siglas planej, orçam e contr representam as variáveis dos artefatos de planejamento. O coeficiente de correlação de Pearson pode variar entre $-1,00$ a $+1,00$. Assim, se o coeficiente for positivo, a associação é positiva, implicando que valores altos (baixos) em uma variável correspondem a valores altos (baixos) da outra variável. Por outro lado, se o coeficiente for negativo, a associação é negativa, o que indica que valores altos (baixos) de uma variável correspondem a valores baixos (altos) da outra variável (Stevenson \& Farias, 1981).

Nota-se que as empresas classificadas no estágio de Nascimento demonstraram uma correlação significativa com todos os artefatos de planejamento (planej, orçam e contr apresentaram sig <0.05). No entanto, essa correlação é negativa, indicando que quanto mais apresentar características nesse estágio menor o nível de planejamento utilizado, ou seja, o estágio em que a empresa se encontra (nascimento) está relacionado negativamente com os artefatos utilizados no seu planejamento. Quanto mais a empresa se encontra em um estágio inicial do ciclo de vida, menor a utilização de artefatos do planejamento, fato esse que corrobora os estudos de Miller e Friesen (1984), que relatam que, no estágio de Nascimento, as empresas que utilizam métodos primitivos de processamento de informação e tomada de decisão apresentam estrutura simples e pouco formalizada.

Analisando-se os estágios de Crescimento, Maturidade e Rejuvenescimento, é possível observar correlação também significativa e ainda, essas associações são todas positivas, o que significa dizer que quanto mais a empresa cresce maior é o uso dos artefatos. Os resultados dos estudos de Miller e Friesen (1984) mostraram que uma das características associadas ao estágio de Crescimento é a formalização dos procedimentos e, no estágio de Maturidade, ocorre significativa melhora no processo de planejamento e também torna a empresa mais burocrática. Além disso, no estágio de Rejuvenescimento, para acompanhar a expansão da empresa, o controle, monitoramento e processamento de informações tornam-se mais sofisticados.

Por outro lado, no estágio em que a empresa entra em declínio, observa-se também correlação significativa, porém negativa para todos os artefatos de planejamento. Novamente os resultados confirmam os achados de Miller e Friesen (1984) em que ficou evidenciado que, nessa fase de Declínio, ocorre diminuição na utilização de artefatos de planejamento, ocorrendo restrição dos instrumentos de controle. Assim, verificase que os resultados encontrados na presente pesquisa convergem com os resultados de Miller e Friesen (1984).

Também convergem com os resultados da pesquisa de Frezatti et al. (2010) em que, nos estágios de Nascimento e Declínio, há uma relação negativa com os artefatos, ou seja, quanto mais a empresa se encontra em um estágio inicial ou final do ciclo de vida, menor a utilização de artefatos do planejamento. Por outro lado, nas fases de Crescimento, Maturidade e Rejuvenescimento apresentaram relação positiva com os artefatos. Assim, quanto mais a empresa se aproxima dessas fases, maior a utilização dos artefatos. Entretanto, Frezatti et al. (2010) não encontrou relação do controle orçamentário em nenhum estágio do ciclo de vida. Nesta pesquisa, existe a relação, entretanto ela é considerada baixa.

Comparando-se os achados com o estudo de Klann et al. (2012), pode-se verificar que, apenas nos estágios de Rejuvenescimento e de Declínio, houve relação significativa; na fase de Rejuvenescimento, houve relação negativa entre o ciclo e a utilização dos artefatos; e na fase de Declínio houve relação positiva, divergindo dos dados desta pesquisa.

\section{Considerações Finais}

Nesta pesquisa identificou a relação dos diferentes estágios do ciclo de vida organizacional com o processo de planejamento das empresas prestadoras de serviços contábeis do Estado de Santa Catarina. Pesquisa descritiva, com abordagem quantitativa, foi realizada por meio de levantamento em uma amostra por acessibilidade de 116 empresas prestadoras de serviços contábeis.

Ao se identificarem os estágios do ciclo de vida organizacional pautados no modelo de Miller e Friesen (1984) das empresas prestadoras de serviços contábeis do Estado de Santa Catarina, constatou-se que das 116 analisadas, 46 encontram-se no estágio do Nascimento, 26 foram classificadas no estágio de 
Rejuvenescimento, 17 Crescimento, 16 Declínio e 11 Maturidade. Desta forma, observou-se que grande parte das empresas é gerida por seus proprietários e com uma estrutura simples e informal.

Ao verificar o nível de utilização do processo de planejamento das empresas, Planejamento Estratégico, Orçamento e Controle Orçamentário, observou-se que 60,5\% utilizam dos artefatos do Planejamento Estratégico, 51,1\% do Orçamento e 47,6\% do Controle Orçamentário. Neste caso, percebese que há organizações que permanecem no planejamento, porém não há a sua execução e controle das metas estabelecidas. O que chama atenção é que apenas a metade das empresas analisadas utiliza-se do Orçamento, mesmo sendo dirigidas por pessoas da área e que conhecem da importância deste instrumento.

Por fim, ao relacionar os estágios do ciclo de vida organizacional pautados no modelo de Miller e Friesen (1984) com o processo de planejamento das empresas prestadoras de serviços contábeis, notou-se que há uma relação negativa entre os estágios de Nascimento e Declínio com o uso dos artefatos, e uma relação positiva com os estágios de Crescimento, Maturidade e Rejuvenescimento. Desta forma, estes resultados corroboraram com a pesquisa de Miller e Friesen (1984), de forma parcial com de Frezatti et al. (2010) e distinta com o estudo realizado por Klann et al. (2012). Tais divergências podem estar atribuídas ao setor analisado, uma vez que Klann et al. (2012) realizou sua pesquisa com empresas do ramo metalúrgico e Frezatti et al. (2010) aplicou em diversos setores.

Desta forma, concluiu-se que é possível a utilização da teoria do ciclo de vida organizacional em organizações contábeis, embora as correlações apresentadas tenham sido consideradas fracas. Ainda assim, percebe-se uma contribuição acadêmica, ao passo que se observou uma relação por meio do ciclo de vida organizacional e o processo orçamentário em empresas prestadoras de serviços contábeis, setor que se mostra incipiente de investigação no cenário nacional ao contemplar a teoria organizacional estudada.

A relação positiva observada nas prestadoras de serviços contábeis, com os estágios de Crescimento, Maturidade e Rejuvenescimento; e negativa, com os estágios de Nascimento e Declínio, corrobora o que a literatura preconiza. Neste sentido, o estudo sinaliza às empresas prestadoras de serviços contábeis e à sociedade que tais organizações, ao apresentarem características de nascimento, tentam se tornar viáveis, porém, sem estabelecimento de formalização de processos, que se mostra na fase de crescimento. Tal formalização de processos e controles se institui na fase de Maturidade, tornando-se mais sofisticados na fase de rejuvenescimento, e com possibilidades de abandono de tais controles na fase de declínio. Para futuras pesquisas, recomenda-se a ampliação do estudo em outras empresas prestadoras de serviços, além das de serviços contábeis, para fins de observar convergências e divergências.

\section{Referências}

Abatecola, G. (2013). Survival or failure within the organisational life cycle. What lessons for managers? Journal of General Management, 38(4), pp. 23-38.

Adizes, I. (1996). Os ciclos de vida das organizações: como e porque as empresas crescem e morrem e o que fazer a respeito. São Paulo: Pioneira.

Anthony, R. N., \& Govindarajan, V. (2006). Sistemas de controle gerencial. Tradução Adalberto Ferreira Neves. São Paulo: Atlas.

Atkinson, A. A., Banker, R. D., Kaplan, R. S., \& Young, S. M. (2008). Contabilidade gerencial. Tradução A. O. M. D. C. Castro, Revisão técnica R. Fama. (2 ed.) São Paulo: Atlas.

Baker, D. D., \& Cullen, J. B. (1993). Administrative reorganization and configurational context: The contingent effects of age, size, and change in size. Academy of Management Journal, 36(6), pp. 1251-1277.

Barros, L. P. S. (2008). Estudo comparativo na área de contabilidade gerencial entre Brasil, México e Espanha.. Dissertação (Mestrado em Ciências Contábeis) - Programa de Pós Graduação em Ciências Contábeis da Universidade Estadual do Rio de Janeiro, Rio de Janeiro, RJ, Brasil. 
Beuren, I. M., \& Pereira, A. M. (2013). Análise de artigos que relacionam ciclo de vida organizacional com controles de gestão. Revista de Administração e Inovação, 10(2), pp.123-143.

Bornia, A. C., \& Lunkes, R. J. (2007). Uma contribuição à melhoria do processo orçamentário. Contabilidade Vista \& Revista, 18(4), pp. 37-59.

Catelli, A. (2001). Controladoria: uma abordagem da gestão econômica - GECON. (2 ed.) São Paulo: Atlas.

Cervo, A. L., \& Bervian, P. A. (1996). Metodologia científica. (4ª ed.) São Paulo: Makron.

Conselho Regional de Contabilidade. (2011). Profissionais Ativos nos Conselhos Regionais de Contabilidade. Recuperado em 01 dezembro, 2011, de http://www3.cfc.org.br/spw/crcs/ConselhoRegionalAtivo.aspx.

Correia, R. B., Gomes, S. M. S., Bruni, A. L., \& Albuquerque, K. S. L. S. (2011). Um estudo empírico sobre ciclo de vida e estágios organizacionais. Anais Congresso USP de Controladoria e Contabilidade, 11, São Paulo, SP, Brasil.

Cunha, P. R., Klann, R. C., \& Lavarda, C. E. F (2013). Ciclo de vida organizacional e controle gerencial: uma análise dos artigos em periódicos internacionais de contabilidade. Revista de Gestão, Finanças e Contabilidade, 3(3), pp. 170-186.

Downs, A. (1967) The Life-Cycle of Bureaus. In Downs, A. Inside Bureaucracy, Little, Brown \& Co., San Francisco, pp. 296-309.

Fávero, L. P., Belfiore, P., Silva, F. L. D., \& Chan, B. L. (2009). Análise de dados: modelagem multivariada para tomada de decisões. Rio de Janeiro: Elsevier.

Freitas, A. A. F., Costa, F. J., \& Barroso, H. C. M. P. (2002). Ciclo de vida organizacional: um estudo no setor de supermercados. Anais EnANPAD, 26, Salvador, BA, Brasil.

Frezatti, F., Relvas, T. R. S., do Nascimento, A. R., Junqueira, E. R., \& Souza B. D. (2010). Perfil de planejamento e ciclo de vida organizacional nas empresas brasileiras. Revista de Administração, 45(4), pp. 383-399.

Frezatti, F. (2007). Orçamento empresarial - planejamento e controle empresarial. (5 ed.) São Paulo: Atlas.

Frezatti, F., Guerreiro, R., Aguiar, A. B. D., \& Gouvêa, M. A. (2007). Análise do relacionamento entre a contabilidade gerencial e o processo de planejamento das organizações brasileiras. Revista de Administração Contemporânea, 11(SPE2), pp. 33-54.

Greiner, L. E. (1972). Evolution and revolution as organizations grow. Harward Business Review, 50(4), pp. 37-46.

Gil, A. C. (2002). Como elaborar projetos de pesquisa. (4ª ed.) São Paulo: Atlas.

Hair Jr, J. F., Babin, B., Money, A. \& Samouel, P. (2005). Fundamentos de métodos de pesquisa em administração. Porto Alegre: Bookman.

Hair Jr., J. F., Black, W. C., Babin, B. J., Anderson, R. E., \& Tatham, R. L. (2009). Análise multivariada de dados. (6 $6^{\mathrm{a}}$ ed.) São Paulo: Bookman.

Katz, D., Kahn, R. L. (1978). The Social Psychology of Organization, Wiley, New York.

Kaufmann, L. (1990). Passaporte para o ano 2000: como desenvolver e explorar a capacidade empreendedora para crescer com sucesso até o ano 2000. São Paulo: McGraw-Hill.

Horngrem, C. T., Sundem, G. L., \& Stratton, W. O. (2004). Contabilidade Gerencial. Traduzido para o português por E. Pereira. São Paulo: Prentice Hall.

Kimberly, J. R., \& Miles, R. H. (1980). The organizational life cycle: issues in the creation, transformation, and decline of organizations. San Francisco, California: Jossey - Bass Publishers.

Kimberly, J. R. (1987). The life cycle analogy and the study of organizations: introduction. In: The organizational life cycle: issues in the creation, transformation and decline of organizations. San Francisco: Jossey-Bass. 
Klann, R. C., Klann, P. A., Postai, K. R., \& Ribeiro, M. J. (2012). Relação entre o ciclo de vida organizacional e o planejamento em empresas metalúrgicas do Município de Brusque-SC. Revista de Contabilidade e Organizações, 6(16), pp.119-142.

Lau, C. M. (1999). The effect of emphasis on tight budget targets and cost control on production and marketing managers' propensity to create slack. The British Accounting Review, 31(4), pp. 415-437.

Lester, D. L., Parnell, J. A., \& Carraher, S. (2003). Organizational life cycle: A five-stage empirical scale. International Journal of Organizational Analysis, 11(4), pp. 339-354.

Lippitt, G. L., Schmidt, W. H. (1967). Crises in a Developing. Harvard Business Rev. Mar. PP. 102-112.

Lyden, F. J. (1975). Using Parson's Functional Analysis in the Study of Public Organization. Admin. Sci. Quart. 20, PP. 59-70.

Lunkes, R. J. (2008). Manual de orçamento. (2a ed.) São Paulo: Atlas.

Machado-Da-Silva, C., Vieira, M., \& Dellagnelo, E. (1992). Controle organizacional: uma abordagem a partir do conceito de ciclo de vida. Anais EnANPAD, 16, Rio Grande do Sul, RS, Brasil, ANPAD, 5, pp.126-138.

Marconi, M. de A., \& Lakatos, E. M. (2005). Técnicas de pesquisa. (6ª ed.) São Paulo: Atlas.

Mário, P. D. C. (2011). Análise discriminante. In: L. J. Corrar, E. Paulo, \& J. M.Dias Filho, (Coord). Análise multivariada para os cursos de Administração, Ciências Contábeis e Economia. São Paulo: Atlas, Cap 4, pp. 232-275.

Marques, A. C. F. (1994). Deterioração organizacional: Como detectar e resolver problemas de deterioração e obsolescência organizacional. São Paulo: Makron Books

Marques, L. (2011). Relação entre o Ciclo de Vida organizacional e o perfil de planejamento em empresas metal mecânicas do Alto e Médio Vale do Itajaí. Trabalho de Conclusão de Curso em Ciências Contábeis, Universidade do Estado de Santa Catarina, Ibirama.

Mattos, M. A. (2008). Investigação das práticas de contabilidade gerencial: um estudo nas empresas prestadoras de serviços contábeis. 104 f. Dissertação (Mestrado em Contabilidade), Programa de Pós-Graduação em Contabilidade, Universidade Federal do Paraná, Curitiba, Paraná.

Miller, D., \& Friesen, P. H. (1984). A longitudinal study of the corporate life cycle. Management Science, 30(10), pp.1161-1183.

Moores, K., \& Yuen, S. (2001). Management accounting systems and organizational configuration: a life-cycle perspective. Accounting, Organizations and Society, 26(4), pp.351-389.

Oliveira, D. P. R. D. (2010). Planejamento estratégico: conceitos, metodologia, práticas. $27^{\mathrm{a}}$ ed. São Paulo: Altas.

Quinn, R. E., \& Cameron, K. (1983). Organizational life cycles and shifting criteria of effectiveness: Some preliminar evidence. Management Science, 29(1), pp. 33-51.

Ramos, A. G. (1981). A Nova ciência das organizações: uma reconceituação da riqueza das nações. Fundação Getúlio Vargas.

Scott, B. R. (1971). IStages of Corporate Development. Part 1, Case no. 9-371-294, Intercollegiate Case Clearing House, Harvard Business School, Boston.

Stevenson, W. J., \& Farias, A. A. (1981). Estatística aplicada à administração. São Paulo: Harper \& Row do Brasil.

Teixeira, G. B., Voese, S. B., \& Teixeira, S. A. (2014). A utilização de artefatos gerenciais por empresas de serviços contábeis em resposta à sua gestão de competências. Anais Congresso ANPCONT, 8 , Rio de Janeiro-RJ, Brasil. 